\title{
Fluorenyl-Loaded Quatsome Nanostructured Fluorescent Probes
}

\author{
Xinglei Liu, ${ }^{\dagger, \S}$ Antonio Ardizzone, ${ }^{\ddagger, \S}$ Binglin Sui, ${ }^{\dagger}$ Mattia Anzola, ${ }^{\ddagger}$ Nora Ventosa, ${ }^{*}, \odot$ Taihong Liu, ${ }^{\dagger}$ \\ Jaume Veciana, ${ }^{*} \ddagger$ and Kevin D. Belfield $*{ }^{*}+(10$ \\ ${ }^{\dagger}$ Department of Chemistry and Environmental Science, College of Science and Liberal Arts, New Jersey Institute of Technology, 323 \\ Martin Luther King, Jr., Blvd., Newark, New Jersey 07102, United States \\ ${ }^{\ddagger}$ Institut de Ciencia de Materials de Barcelona (CSIC)-CIBER-BBN, Campus Universitari de Bellaterra, 08193 Cerdanyola, Spain
}

\section{Supporting Information}

ABSTRACT: Delivery of hydrophobic materials in biological systems, for example, contrast agents or drugs, is an obdurate challenge, severely restricting the use of materials with otherwise advantageous properties. The synthesis and characterization of a highly stable and water-soluble nanovesicle, referred to as a quatsome (QS, vesicle prepared from cholesterol and amphiphilic quaternary amines), that allowed

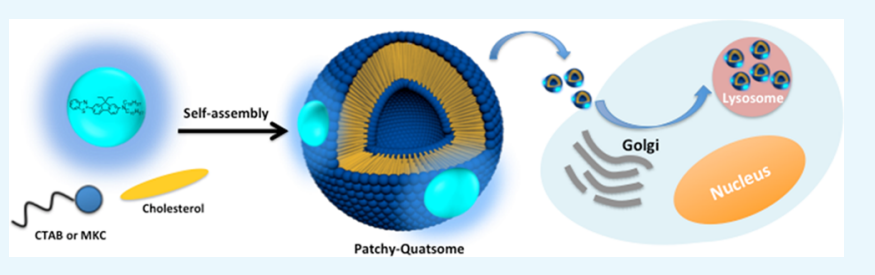
the nanostructuration of a nonwater soluble fluorene-based probe are reported. Photophysical properties of fluorenyl-quatsome nanovesicles were investigated via ultraviolet-visible absorption and fluorescence spectroscopy in various solvents. Colloidal stability and morphology of the nanostructured fluorescent probes were studied via cryogenic transmission electronic microscopy, revealing a "patchy" quatsome vascular morphology. As an example of the utility of these fluorescent nanoprobes, examination of cellular distribution was evaluated in HCT 116 (an epithelial colorectal carcinoma cell line) and COS-7 (an African green monkey kidney cell line) cell lines, demonstrating the selective localization of C-QS and M-QS vesicles in lysosomes with high Pearson's colocalization coefficient, where C-QS and M-QS refer to quatsomes prepared with hexadecyltrimethylammonium bromide or tetradecyldimethylbenzylammonium chloride, respectively. Further experiments demonstrated their use in time-dependent lysosomal tracking.

\section{INTRODUCTION}

The development of new organic molecular probes with excellent photophysical properties and high fluorescence quantum yields is of considerable interest to many research areas including one- and two-photon fluorescence microscopy, fluorescence-based sensing methodologies, and cancer therapy. ${ }^{1-8}$ However, the hydrophobicity and poor availability in aqueous media of a preponderance of organic fluorescent molecules often severely limit their utility in biological applications, instigating a number of approaches to overcome this challenge. ${ }^{1,9,10}$ The chemical modification of nonwater soluble fluorene derivatives, via the addition of carboxylic ${ }^{1}$ or salicylic acid moieties, ${ }^{11}$ improved their solubility in biological media, overcoming in part this drawback. Alternative strategies consist of dispersing the hydrophobic probes in water as nanoparticles (NPs), for example, or by encapsulation in micelles, ${ }^{12}$ conjugation to polymers, or incorporation in hydrophilic nanostructures. ${ }^{13,14}$ Here, we present a new strategy to disperse in aqueous media a hydrophobic fluorene derivative. This strategy consists in the nanostructuration of the dye in a class of small unilamellar vesicles, referred to as a quatsome (QS), in which the bilayer membrane is composed of a quaternary ammonium surfactant and a sterol. ${ }^{15}$ Quatsomes are generally very stable, and they have been recently studied and developed as a multifunctional carrier of bioactive molecules. $^{16}$
Lysosomes are terminal degradative compartments of mammalian cells that play significant roles in cellular metabolism, endocytosis, and the synthesis/assembly of hydrolases involved in macromolecule digestion. ${ }^{17,18}$ Dysfunction of lysosomes result in severe problems, including inflammation, cancer, and specific lysosomal storage disease, among others. ${ }^{19-24}$ Therefore, efforts have been devoted to design and synthesize effective fluorescent probes for the study of lysosome trafficking in cancer invasion and metastasis in recent years. $^{25,26}$

In this work, a hydrophobic fluorene derivative, DiC18 (Scheme 1), possessing desirable photophysical properties, was designed and synthesized. Dye-loaded QSs were prepared by processing the dye along with the surfactant, cetyltrimethylammonium bromide (CTAB) or tetradecyldimethylbenzylammonium chloride (MKC), and cholesterol via a compressed $\mathrm{CO}_{2}$ methodology named depressurization of an expanded liquid organic solution-suspension (DELOS-SUSP), ${ }^{27}$ which leads to the formation in a single step of a highly homogeneous dispersion of functionalized quatsomes $(<100 \mathrm{~nm})$ in an aqueous environment. DiC18-loaded quatsomes exhibited, in both cases, advantageous photophysical characteristics and high selectivity for the lysosomes of HCT 116 and COS-7 cells,

Received: June 13, 2017

Accepted: July 18, 2017

Published: August 2, 2017 
Scheme 1. Synthetic Route for Preparation of $\mathrm{DiC}^{a} 8^{a}$
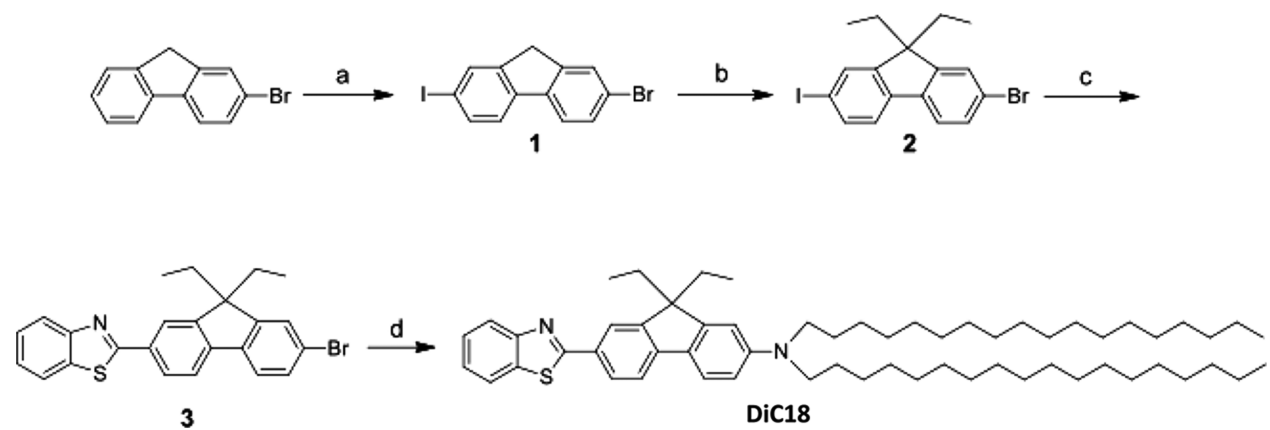

${ }^{a}$ Reagents and conditions: (a) $\mathrm{I}_{2}, \mathrm{KIO}_{3}, \mathrm{HOAc}, \mathrm{H}_{2} \mathrm{SO}_{4}, \mathrm{H}_{2} \mathrm{O}, 100{ }^{\circ} \mathrm{C}, 2 \mathrm{~h}, 80 \%$; (b) bromoethane, $\mathrm{KI}, \mathrm{KOH}$, dimethyl sulfoxide (DMSO), room temperature, $12 \mathrm{~h}, 73 \%$; (c) 2-(tri- $n$-butylstannyl)benzothiazole, $\mathrm{Pd}\left(\mathrm{PPh}_{3}\right)_{4}$, toluene $(\mathrm{TOL})$, reflux, $8 \mathrm{~h}, 43 \%$; $(\mathrm{d})$ dioctadecylamine, $\mathrm{Pd}(\mathrm{OAc})_{2},(t$ $\mathrm{Bu})_{3} \mathrm{P}, t-\mathrm{BuONa}$, toluene, reflux, $16 \mathrm{~h}, 84 \%$.

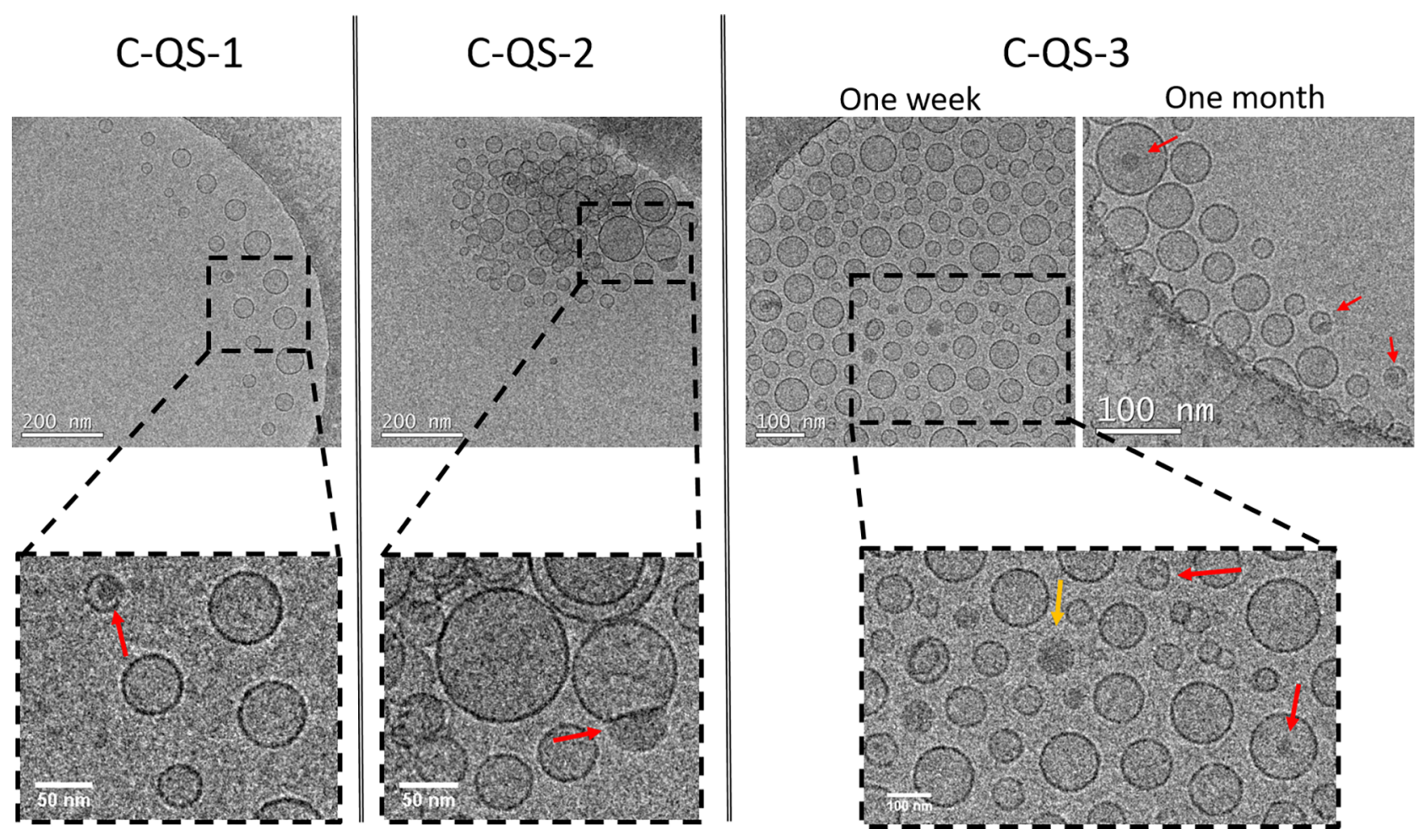

Figure 1. CryoTEM micrographs of DiC18-loaded quatsomes at increasing loading of DiC18: (left) C-QS-1; (middle) C-QS-2; (right) C-QS-3 1 week and 1 month after the preparation. Enlargements of the images are shown in the bottom part of the picture. The red arrows indicate patchyquatsomes, whereas the blue ones indicate other supramolecular organization of DiC18.

suggesting their potential as probes for short- and long-term lysosomal labeling and tracking.

\section{RESULTS AND DISCUSSION}

Synthetic Strategy. The synthesis of target compound DiC18 (Scheme 1) began with 2-bromo-9H-fluorene, which was used to prepare 2-bromo-7-iodo-9H-fluorene (1) according to a literature procedure. ${ }^{28}$ Fluorene 2 was obtained from substitution of the 9-position benzylic hydrogens of 2-bromo-7iodo-9H-fluorene with bromoethane. ${ }^{29}$ The Stille coupling reaction was performed between 2 and 2 -(tri- $n$-butylstannyl)benzothiazole with $\mathrm{Pd}\left(\mathrm{PPh}_{3}\right)_{4}$, as a catalyst, to prepare 3 . Benzothiazolylfluorene 3 was reacted with $N, N$-di-n-octadecylamine via an Ullmann coupling reaction to produce the final product, DiC18, as a yellow oil, which is nonsoluble in water but highly soluble in organic solvents of different polarities.
Preparation of DiC18-Loaded Quatsomes. DiC18loaded quatsomes were prepared by the $\mathrm{CO}_{2}$-based method, DELOS-SUSP. First, cholesterol and DiC18 were dissolved in $\mathrm{EtOH}$ and then added to a high-pressure vessel, previously heated at $T_{\mathrm{w}}=308 \mathrm{~K}$. Afterward, $\mathrm{CO}_{2}$ was added until reaching the working pressure $\left(P_{\mathrm{w}}=10 \mathrm{MPa}\right)$, to obtain a $\mathrm{CO}_{2^{-}}$ expanded solution of the compounds. In the last stage, the DiC18-loaded quatsomes were formed by depressurizing the $\mathrm{CO}_{2}$-expanded solution over an aqueous solution of the surfactant ( $\mathrm{CTAB}$ or $\mathrm{MKC})$. The obtained samples were then purified by diafiltration to remove the EtOH and excess surfactant. This procedure enabled the preparation of aqueous suspensions of quatsomes based on cholesterol and CTAB, as the surfactant, with DiC18 loadings ( moles $_{\mathrm{DiC} 18} /\left(\right.$ moles $_{\text {surfactant }}$ + moles $\left._{\text {cholesterol }}\right)$ ) of $0.9 \times 10^{-3}, 7.0 \times 10^{-3}$, and $1.3 \times 10^{-2}$ for samples C-QS-1, -2, and -3, respectively. The same procedure 
was followed with another quaternary ammonium surfactant, MKC, which should be more suitable for parenteral drug delivery than $\mathrm{CTAB}$, as it is more biocompatible obtaining dyeloaded QSs with DiC18 loadings of $0.5 \times 10^{-3}, 4.8 \times 10^{-3}$, and $9.7 \times 10^{-3}$ for samples M-QS-1, $\mathbf{- 2}$, and $\mathbf{- 3}$, respectively (Table S1).

Colloidal Stability and Morphology of DiC18-Loaded Quatsomes. Figure 1 shows cryogenic transmission electronic microscopy (CryoTEM) micrographs of samples C-QS-1, -2, and -31 week after their preparation, which appeared mostly of round-shaped nanovesicles with average hydrodynamic diameters of 70, 58, and $60 \mathrm{~nm}$, as measured by dynamic light scattering (DLS) (see Table S2), respectively. The zeta potential of the three samples was higher than $70 \mathrm{mV}$, and average sizes were maintained over 2 months, supporting the very high colloidal stability of such systems (Table S2). No changes were detected in the morphology of the samples, as shown in the case of C-QS-3 comparing 1 week versus 1 month (Figure 1, right). Similarly to C-QS, M-QS-1, -2, and -3 samples also possessed good colloidal stabilities.

CryoTEM images illustrate that DiC18-loaded quatsomes constituted a mix of different nanostructures. Interestingly, along with small quatsomes, the presence of some vesicles with a "patch" was detected (in all of the cases only one patch per vesicle was detected). The patches (indicated with a red arrow in Figure 1) can be recognized due to the higher contrast to electrons in the cryoTEM images. This new structure, named patchy-quatsomes (patchy-QSs), has not been reported in previously studied quatsomes. $15,16,27$ The presence of this particular architecture is attributed to the aggregation on the surfaces of QSs of the nonwater soluble, nonamphiphilic DiC18 molecules, favored by the multiple van der Waals interactions among their alkyl chains and the $\mathrm{CH}-\mathrm{p}$ interactions with the aromatic fluorene cores, minimizing the direct contact of most of the DiC18 molecules with the aqueous media. It is hard at this time to speculate on the exact composition/structure of these patches because they can be formed only by $\mathrm{DiC} 18$ or a combination of $\mathrm{DiC} 18$ and surfactant or cholesterol molecules that could stick to the QS surfaces providing isolation from water molecules. Nevertheless, a point worth mentioning of such new structures is the fact that the presence of patches is advantageous for optical applications because they enable larger dye concentrations in aqueous suspensions without quenching or compromising too much their fluorescence properties (vide infra).

Along with QSs and patchy-QSs, other sparse nonvesicular structures were detected, indicated by the blue arrow in Figure 1 (bottom right). These structures, never detected in the case of plain QSs made with cholesterol and CTAB, are ascribed to supramolecular assemblies of $\mathrm{DiC18}$ but were completely isolated and not bound to the vesicles, in contrast to that observed for patchy-QSs. DiC18-loaded QSs made with MKC/ cholesterol showed similar structures, as shown in Figure S1.

Photophysical Properties. Photophysical properties of DiC18 were investigated in solvents with different polarities including DMSO, acetonitrile (ACN), toluene (TOL), dichloromethane (DCM), cyclohexane (CHX), and hexane (HEX). The linear absorption, emission spectra, and photophyscial properties of DiC18 are shown in Figure 2 and summarized in Table 1 . The absorption spectra for DiC18 displayed maximum intensity in the range of $387-411 \mathrm{~nm}$, with only nominal variation as a function of solvent polarities. In comparison, fluorescence emission of this asymmetrical $(\mathrm{D}-\pi-$

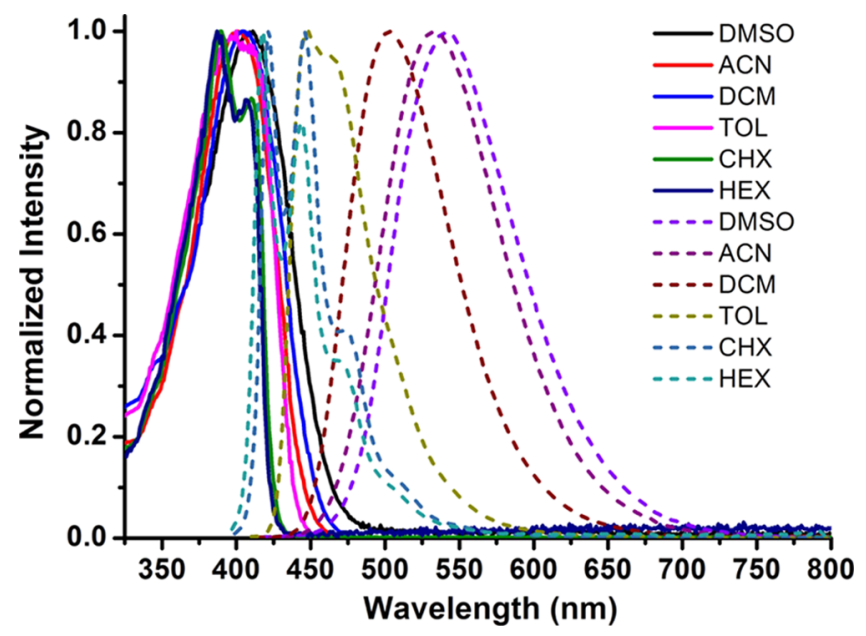

Figure 2. Normalized absorption (solid lines) and emission spectra (dashed lines) of DiC18 in DMSO, ACN, DCM, TOL, CHX, and HEX.

A) compound results from excitation in the main absorption band, exhibiting a bathochromic shift with strong solvent polarity dependencies, where $\mathrm{D}$ and A refer to electron-donor and electron-acceptor moieties, respectively, joined by a $\pi$ conjugated structure. DiC18 emission exhibited a well-resolved vibrational structure with a maximum at $418 \mathrm{~nm}$ in a nonpolar solvent (hexane) and was replaced by a broader, structureless peak with the maximum shifted to $541 \mathrm{~nm}$ in a polar solvent (DMSO). The solvatochromic behavior of $\mathrm{DiC18}$ is consistent with some other fluorene derivatives that are sensitive to the environmental polarity. ${ }^{11,30-32}$ The compound exhibited excellent quantum yield in different solvents (all close to 1), indicating that it is a promising candidate for further chemical and biological applications.

The photophysical properties of C-QS-1, -2, and -3 and MQS-1, -2, and -3 are summarized in Table 2. The steady-state absorbance, excitation, emission, and excitation anisotropy of C-QS-1, -2, and -3 are presented in Figure 3. As a consequence of their nanometric size distribution, quatsomes scatter light in the ultraviolet-visible (UV-vis) range. Especially at low DiC18 loading (C-QS-1, Figure 3a, and M-QS-1, Figure S2), for which the absorption to scattering ratio is low, the absorption spectrum may be misinterpreted. For this reason, as well as to have an estimation of the fluorescence quantum yield of the system, scattering has been subtracted, as explained in Experimental Section. The absorption spectra of the other two samples (C-QS-2 and -3) are shown as originally acquired, without any mathematical treatment. The slight positive solvatochromism in absorption (from 391 to $394 \mathrm{~nm}$ for CQS-1 to -3) and emission (from 452 to $461 \mathrm{~nm}$ for C-QS-1 to $-3)$, as a function of increasing the DiC18 loading in the QSs, suggests a change in the polarity around the fluorophore.

However, normalized excitation spectra of C-QS-1, -2, and -3 and DiC18 in THF were well overlapped. The excitation anisotropy of DiC18-loaded QSs decreased at a higher loading of the dye (Figure 3d), likely as an effect of the homoresonance energy transfer between DiC18 molecules experiencing close proximity at higher loadings. The higher anisotropy showed by the C-QS samples compared to that by DiC18 in glycerol proves that the incorporation in QSs effectively restricted its rotational diffusion, reducing the possibility of nonradiative decay. The decrease of quantum yields and lifetime (Figure S2) 
Table 1. Photophysical Properties for Fluorene DiC18

\begin{tabular}{|c|c|c|c|c|c|c|}
\hline & HEX & $\mathrm{CHX}$ & TOL & DCM & $\mathrm{ACN}$ & DMSO \\
\hline$\lambda_{\mathrm{ab}}{ }^{a}(\mathrm{~nm})$ & 387,406 & 389,410 & 400 & 404 & 401 & 411 \\
\hline$\lambda_{\mathrm{em}}{ }^{a}(\mathrm{~nm})$ & 418,444 & 422,446 & 447 & 503 & 532 & 541 \\
\hline$\Delta \lambda^{b}(\mathrm{~nm})$ & 31 & 33 & 47 & 99 & 131 & 130 \\
\hline$\varepsilon_{\max }{ }^{c}\left(10^{3} \mathrm{M}^{-1} \mathrm{~cm}^{-1}\right)$ & 52 & 52 & 46 & 40 & 44 & 38 \\
\hline$\Phi_{\mathrm{f}}^{d}$ & 0.92 & 1.00 & 1.00 & 1.00 & 1.00 & 1.00 \\
\hline$T^{e}$ (ns) & 1.33 & 1.35 & 1.44 & 2.10 & 2.39 & 2.44 \\
\hline
\end{tabular}

${ }^{a}$ Absorption and emission maxima $\pm 1 \mathrm{~nm} .{ }^{b}$ Stokes shift $\pm 2 \mathrm{~nm} .{ }^{c}$ Molar absorptivity. ${ }^{d}$ Fluorescence quantum yield $\pm 10 \%$. ${ }^{e}$ Fluorescence lifetimes

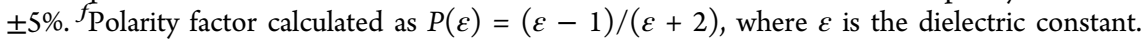

Table 2. Photophysical Properties of C-QS and M-QS Nanovesicles

$\begin{array}{lccccc} & \begin{array}{c}\lambda_{\mathrm{ab}}{ }^{a} \\ (\mathrm{~nm})\end{array} & \begin{array}{c}\lambda_{\mathrm{em}}{ }^{a} \\ (\mathrm{~nm})\end{array} & \begin{array}{c}\Delta \lambda^{b} \\ (\mathrm{~nm})\end{array} & \Phi_{\mathrm{f}}{ }^{c} & \tau^{d}(\mathrm{~ns}) \\ \begin{array}{l}\text { DiC18 in } \\ \text { tetrahydrofuran }\end{array} & 400 & 482 & 82 & 0.85 & 1.80 \\ \begin{array}{l}\text { (THF) } \\ \text { C-QS-1 }\end{array} & 392 & 431, & 60 & 0.46 & 2.45 \\ \text { C-QS-2 } & 394 & 455 & 61 & 0.37 & 2.30 \\ \text { C-QS-3 } & 394 & 461 & 67 & 0.21 & 0.73(46.48 \%) \\ & & & & & 3.05(53.52 \%) \\ \text { M-QS-1 } & 394 & 430, & 59 & 0.40 & 2.28 \\ \text { M-QS-2 } & 395 & 459 & 64 & 0.33 & 2.06 \\ \text { M-QS-3 } & 395 & 468 & 73 & 0.25 & 0.87(57.60 \%) \\ & & & & & 3.35(42.40 \%) \\ \text { DiC18 NPs } & 395 & 472 & 77 & 0.1 & \end{array}$

${ }^{a}$ Absorption and emission maxima $\pm 1 \mathrm{~nm}$. ${ }^{b}$ Stokes shift $\pm 2 \mathrm{~nm}$.

${ }^{c}$ Fluorescence quantum yield $\pm 10 \%$. ${ }^{d}$ Fluorescence lifetimes $\pm 5 \%$. for QSs with increasing loading of DiC18 further supported the homoenergy transfer process. Absorption, excitation, and emission spectra of DiC18 nanoparticles, prepared by reprecipitation, are displayed in Figure S3. In comparison with DiC18-loaded QSs, the emission band for the NPs exhibited a slight bathochromic shift to $472 \mathrm{~nm}$, and the fluorescence quantum yield decreased from 0.46 for C-QS-1 to 0.1 for the NPs. The desirable photophysical properties and generally high quantum yields of DiC18-loaded QSs indicated that quatsomes are promising vehicles to disperse hydrophobic probes in aqueous environments, achieving bright and stable fluorescent architectures that possess significant potential in fluorescence bioimaging. Similar results were obtained for MKC-based QSs (M-QS, Table 2), and their spectra are shown in Figure S2.

The optical stability of the C-QS and M-QS samples was studied by monitoring their absorption spectra over time (Figure S4). Notably, no changes in the absorption bandshapes
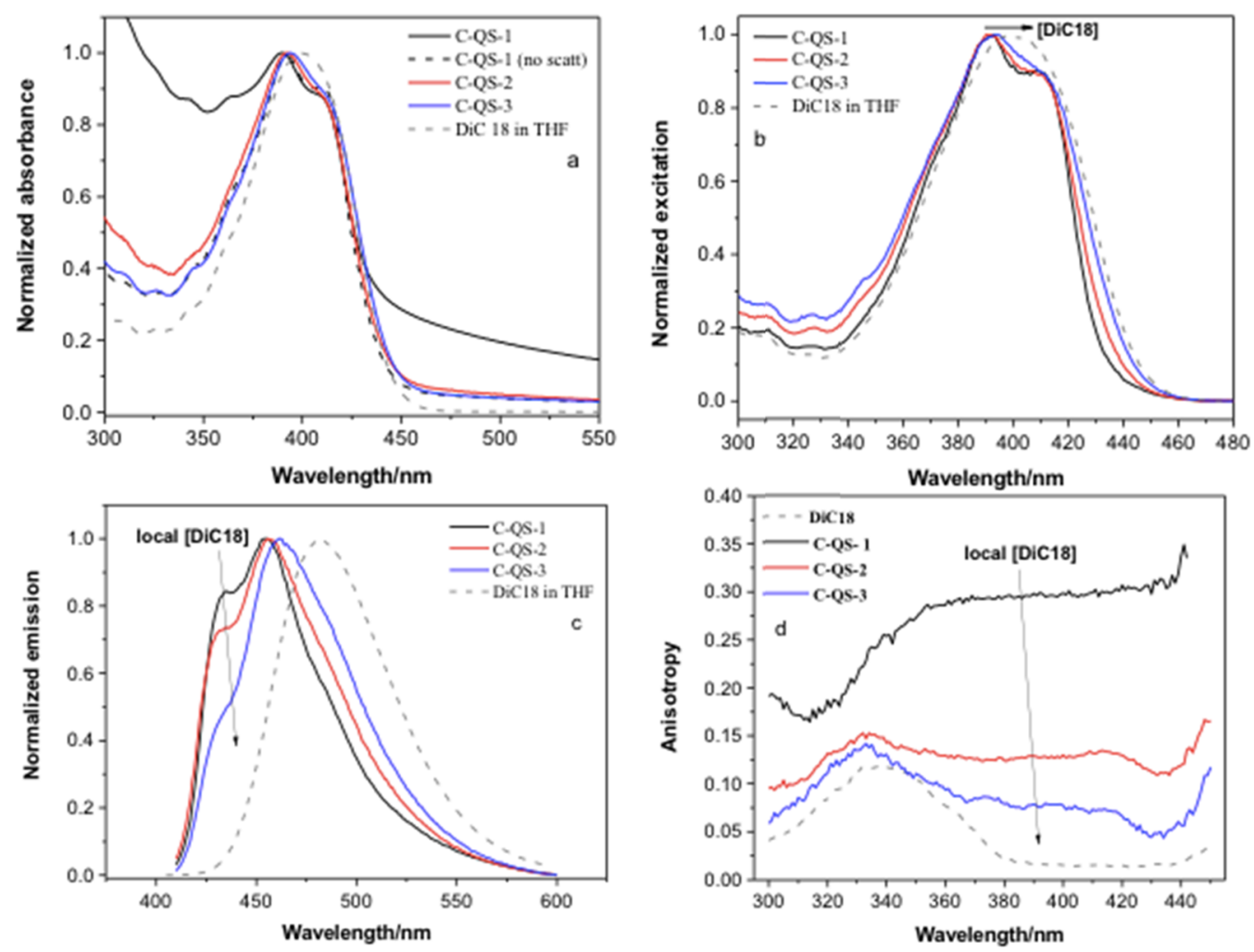

Figure 3. Normalized (a) absorption; (b) excitation; and (c) emission spectra of DiC18 in THF, C-QS-1, -2, and -3 in Milli-Q water. (d) Excitation anisotropy of DiC18 and C-QS-1, -2, and -3 in glycerol. 
or in intensities were detected over 2 months, evidencing the superior stability of these fluorescent nanostructures.

pH Sensitivity Measurements. A primary function of lysosomes in cells is to work as a digestive system by using an array of enzymes that are capable of breaking down many types of biological macromolecules. It is essential for a lysosomal probe to be stable in an acidic environment because all of the lysosomal enzymes are acidic hydrolases, which are active at the acidic $\mathrm{pH}$ (about 5) that is maintained within lysosomes. ${ }^{17,33}$ The $\mathrm{pH}$ stability of C-QS-1, -2, and -3 and M-QS-1, -2, and -3 was investigated by measuring the steady-state absorption and emission spectra in a phosphate-buffered saline (PBS) solution at various pHs. As illustrated in Figure S6, only small fluctuations were observed in the absorption and emission spectra, indicating the good stability of C-QS-1, -2, and -3 and M-QS-1, -2, and -3 over the $\mathrm{pH}$ range of 4.10-10.32 (representative data for C-QS-3 and M-QS-3 are provided).

Cell Viability. To ascertain the potential utility of fluorescent probe DiC18 and DiC18-loaded QSs for cellular imaging, cell viability assays in HeLa and HCT 116 cells were conducted via the 3-(4,5-dimethylthiazol-2-yl)-5-(3-carboxymethoxyphenyl)-2-(4-sulfophenyl)-2H-tetrazolium (MTS) assay. ${ }^{17,31,36}$ Figure S7 shows the viability data for HCT 116 cells after a $24 \mathrm{~h}$ incubation with several concentrations of DiC18. Low cytotoxicity was observed up to a concentration of $40 \mu \mathrm{M}$. Cell viability experiments in HeLa cells were performed for C-QS-1, -2, and -3 and M-QS-1, -2, and -3 (Figure 4). $\mathrm{CTAB}$ and $\mathrm{MKC}$ are quaternary ammonium surfactants, and their cytotoxicity to different human cells was previously reported. ${ }^{34,35}$ The results show that the effect of DiC18 loading is negligible, and the cytotoxicity is governed by the concentration of the surfactant (CTAB or $\mathrm{MKC})$. Good viability was obtained for $\mathrm{C}-\mathrm{QS}$ at a concentration of $0.022 \mathrm{mM}$

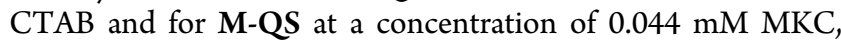
respectively.

Cell Imaging and Cellular Colocalization Study. For demonstration purposes, fluorescence imaging was performed in an epithelial colorectal carcinoma cell line, HCT 116, for organic probe DiC18 and QS probes C-QS-1, -2, and -3 and M-QS-1, -2, and -3. On the basis of the cell viability test results, $20 \mu \mathrm{M}$ of $\mathrm{DiC} 18$ and various amounts of C-QS-1, -2, and -3 and M-QS-1, -2, and -3 were employed for cell incubation and fluorescence imaging. Cells treated with $\mathrm{DiC} 18$ for $2 \mathrm{~h}$ displayed no fluorescence upon excitation (Figure S8), likely because $\mathrm{DiC18}$, after dissolution in DMSO, underwent aggregation when diluted by a growth medium and was not uptaken by cells. In comparison, cells incubated with C-QS-3 and M-QS-3 provided bright images, manifesting the good biological compatibility of QSs and the capability of introducing organic fluorescent molecules into cells for in vitro (Figure 5) or in vivo applications. Images acquired from cells treated with C-QS-1 and -2 and M-QS-1 and -2 showed weaker fluorescence due to the low loading of DiC18 in QSs (not shown) and hence studies focused on C-QS-3 and M-QS-3.

Subsequently, to demonstrate the cellular distribution of CQS-3 and M-QS-3, colocalization experiments were conducted in both HCT 116 and COS-7 cells, two commonly employed cell lines. ${ }^{17,18,25}$ The lysosomal marker, Lysotracker Red, and the mitochondria marker, Mitotracker Red, were employed for comparison to determine potential organelle selectivity. Fluorescence images collected for cells coincubated with commercial markers and QSs indicate that the localization of C-QS-3 and M-QS-3 was coincident to that of Lysotracker Red

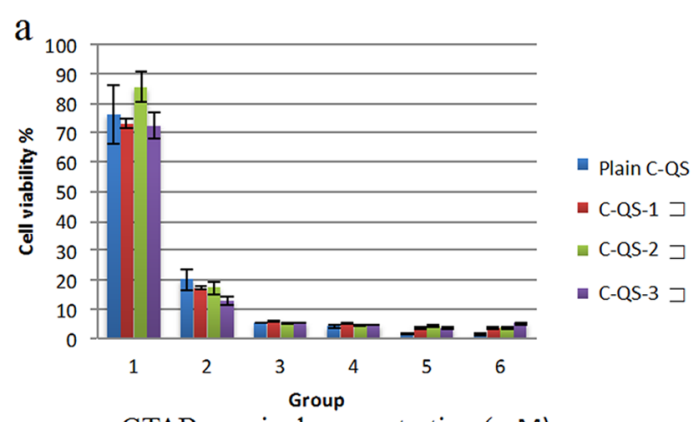

CTAB nominal concentration (mM)

\begin{tabular}{|c|c|c|c|c|c|c|} 
Group & $\mathbf{1}$ & $\mathbf{2}$ & $\mathbf{3}$ & $\mathbf{4}$ & $\mathbf{5}$ & $\mathbf{6}$ \\
\hline $\begin{array}{c}\text { CTAB } \\
\text { (mM) }\end{array}$ & 0.022 & 0.044 & 0.88 & 0.175 & 0.35 & 0.70 \\
\hline
\end{tabular}

$\mathrm{b}_{100}$

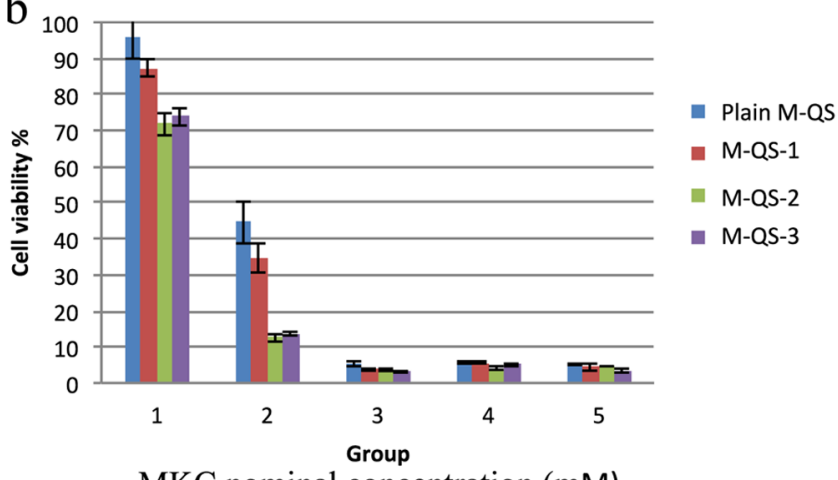

MKC nominal concentration (mM)

\begin{tabular}{|c|c|c|c|c|c|} 
Group & $\mathbf{1}$ & $\mathbf{2}$ & $\mathbf{3}$ & $\mathbf{4}$ & $\mathbf{5}$ \\
\hline $\begin{array}{l}\text { MKC } \\
(\mathbf{m M})\end{array}$ & 0.044 & 0.088 & 0.18 & 0.35 & 0.7 \\
\hline
\end{tabular}

Figure 4. Cell viability assay of HeLa cells incubated with (a) plain CQS and C-QS-1, -2, and -3; (b) plain M-QS and M-QS-1, -2, and -3, at various concentrations.

(Figures 6, 7, S9, and S10). Pearson's correlation coefficient, determined using freely available Fiji software, for C-QS-3 and M-QS-3 relative to Lysotracker Red was 0.89 and 0.92, respectively, whereas relative to Mitotracker Red the values were 0.32 and 0.30 , respectively, demonstrating high selectivity toward lysosomes.

Time-Dependent Lysosome Tracking Experiment. Time-dependent lysosome tracking experiments were performed to assess the intracellular retention of quatsome probes in cancer cells. ${ }^{17,25}$ After a $2 \mathrm{~h}$ treatment with Lysotracker Red and C-QS-3 or M-QS-3, HCT 116 cells were incubated for an additional 2, 4, and 6 h, respectively. As shown in Figures 8 and 9 , there remained significant fluorescence in cells $8 \mathrm{~h}$ after initial incubation with the fluorenyl QS probes, maintaining its colocation with lysosomal markers, suggesting that C-QS-3 and M-QS-3 are promising candidates for long-term lysosomal tracking applications that can be used for monitoring lysosome distributions, activities, and related cell death.

\section{CONCLUSIONS}

A new lysosome-specific fluorescent nanostructured probe has been obtained by using quatsomes to stably disperse a nonwater soluble fluorene derivative (DiC18) in aqueous media. Despite the morphological heterogeneity, QS probes C- 


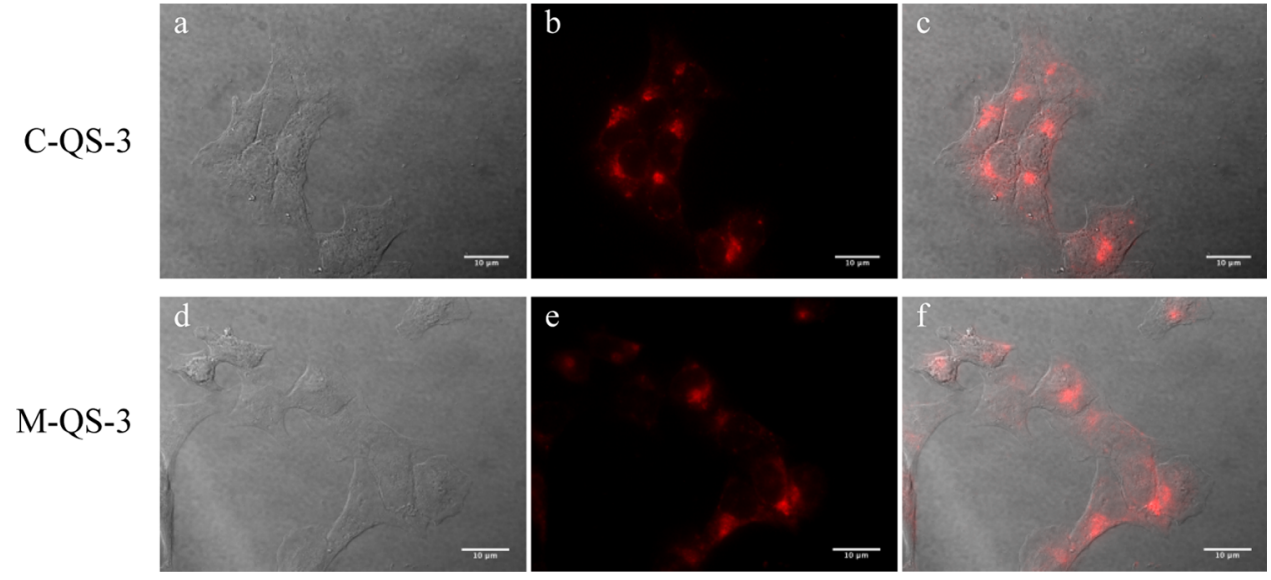

Figure 5. Fluorescence images of HCT 116 cells incubated with C-QS-3 (0.022 mM, 2 h) and M-QS-3 (0.044 mM, 2 h). (a, d) Differential interference contrast (DIC), (b, e) fluorescence images, and (c, f) merged images; $60 \times$ oil immersion objective.

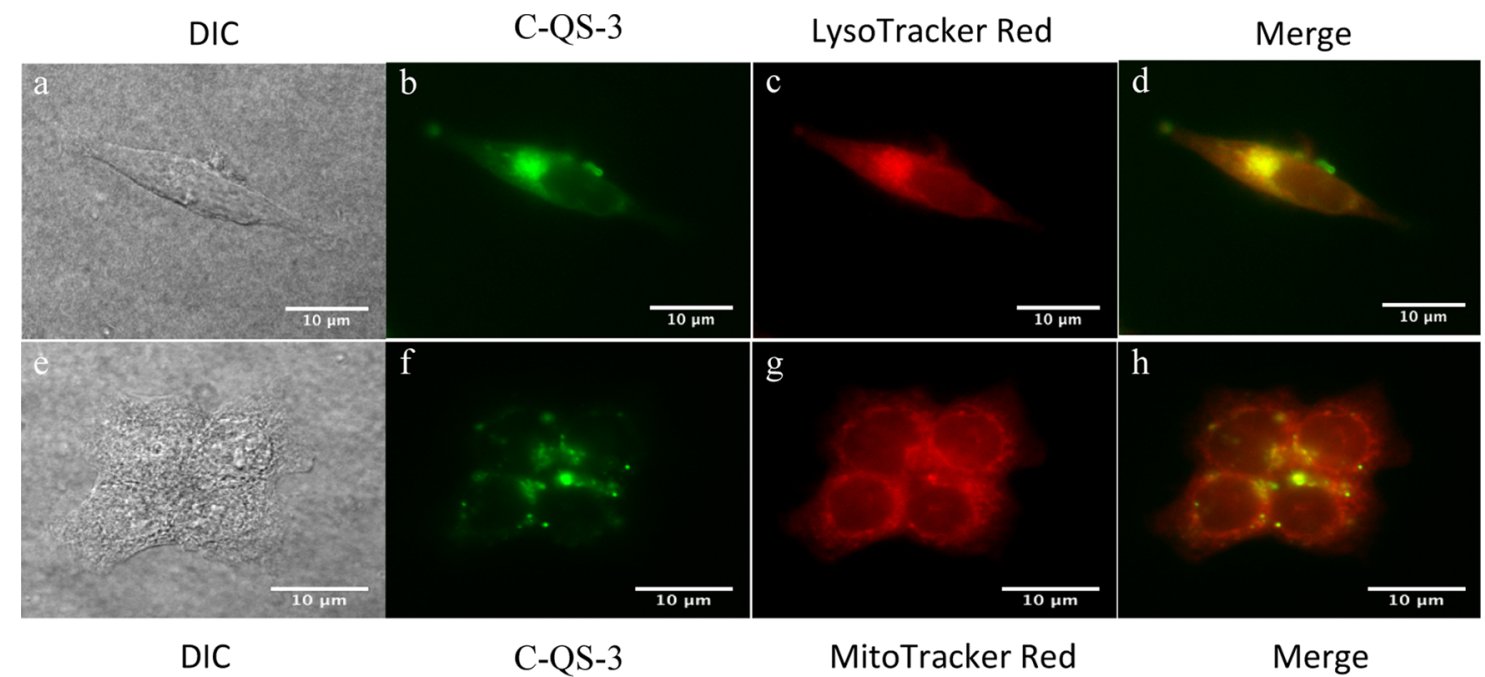

Figure 6. Fluorescence and colocalization images of HCT 116 cells incubated with C-QS-3 (0.022 mM, 2 h), and Lysotracker Red (75 nM, 2 h) or Mitotracker Red (400 nM, 45 min). (a, e) DIC; fluorescence images of (b, f) C-QS-3, (c) Lysotracker Red, (g) Mitotracker Red, and (d, h) merged images; $60 \times$ oil immersion objective.
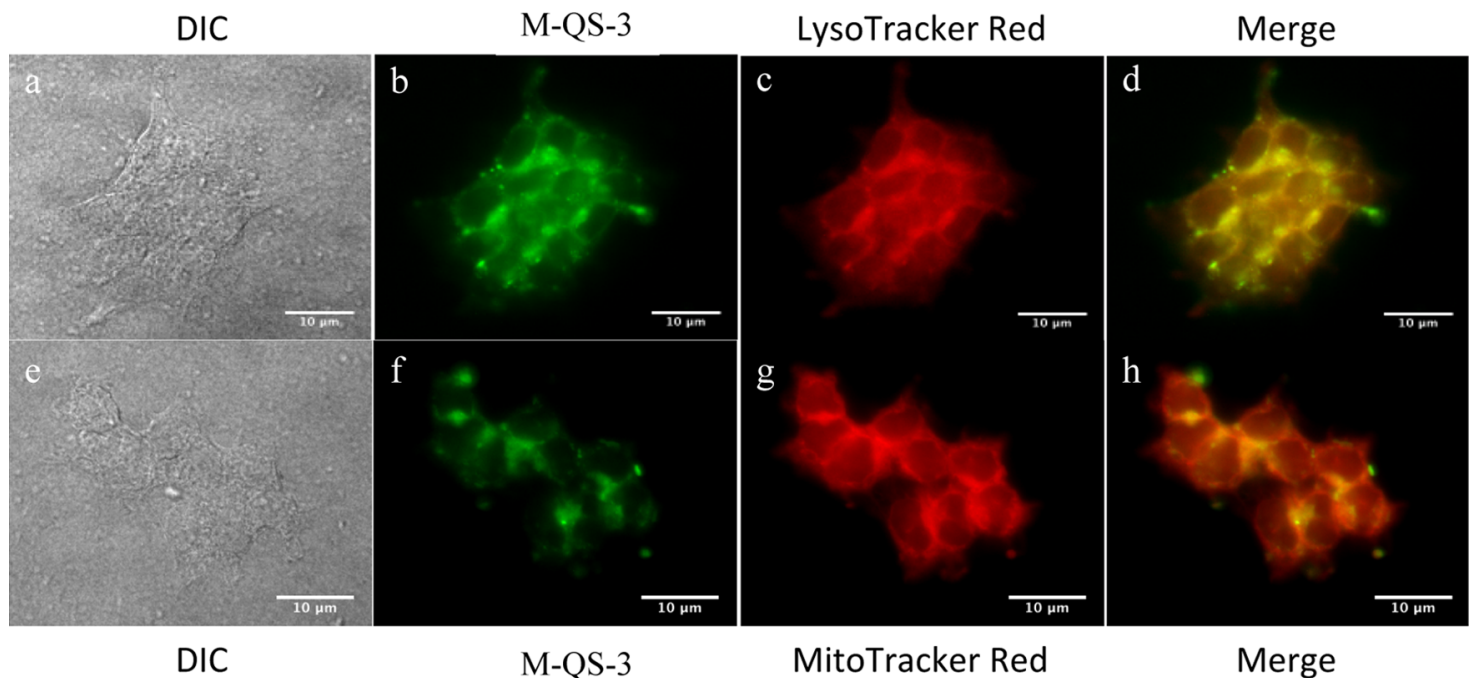

Figure 7. Fluorescence and colocalization images of HCT 116 cells incubated with M-QS-3 (0.044 mM, 2 h) and Lysotracker Red (75 nM, 2 h) or Mitotracker Red (400 nM, 45 min). (a, e) DIC; fluorescence images of (b, f) M-QS-3, (c) Lysotracker Red, (g) Mitotracker Red, and (d, h) merged images; $60 \times$ oil immersion objective. 


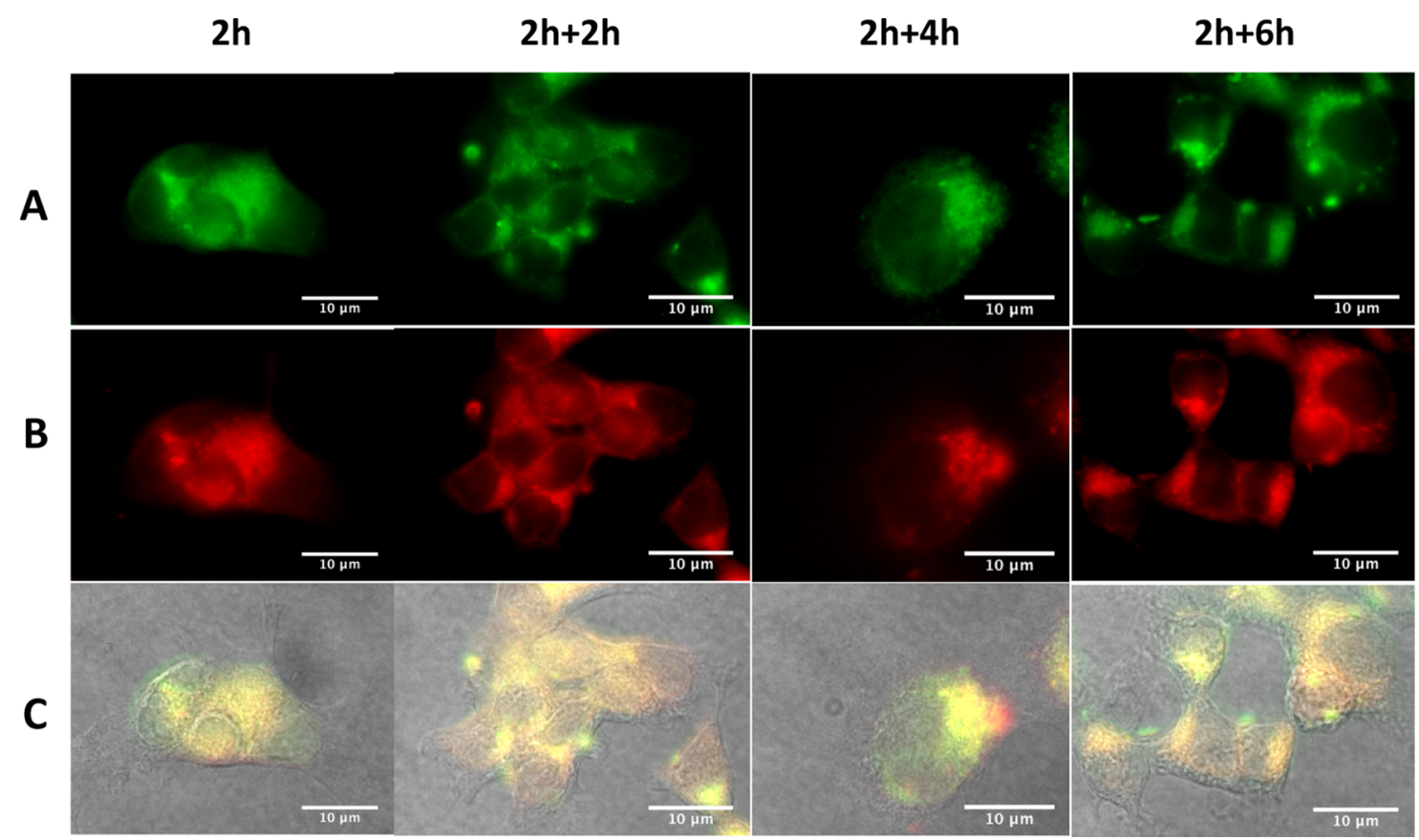

Figure 8. Time-dependent lysosome tracking of HCT 116 cells incubated with C-QS-3 (0.044 mM, 2 h) and Lysotracker Red (75 nM, 2 h) Fluorescence images of (A) C-QS-3, (B) Lysotracker Red, and (C) merged images; 60X oil immersion objective.

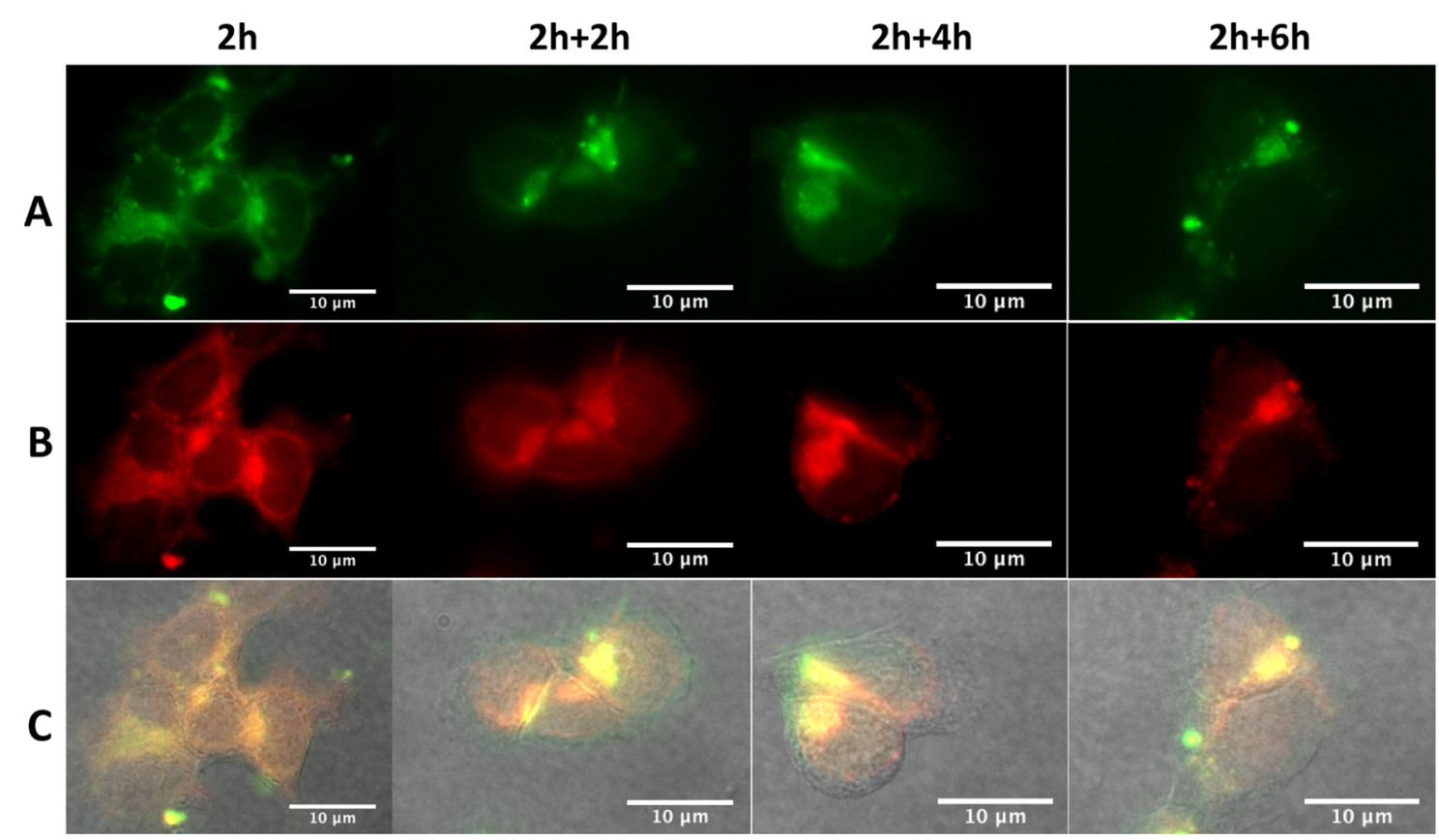

Figure 9. Time-dependent lysosome tracking of HCT 116 cells incubated with M-QS-3 (0.044 mM, 2 h) and Lysotracker Red (75 nM, 2 h). Fluorescence images of (A) M-QS-3, (B) Lysotracker Red, and (C) merged images; 60× oil immersion objective.

QS-1, -2, and -3 and M-QS-1, -2, and -3 formed patchy quatsomes and exhibited good stability, both in terms of colloidal and spectral properties, over 2 months. Fluorescence quantum yields were generally high for the fluorenyl-based probes, and fluorescence anisotropy spectra indicated that DiC18 exists in a highly anisotropic environment in the patchyQSs. The study of their photophysical properties indicates that these QS nanovesicles are desirable fluorescent probes for in vitro cell imaging. The cytotoxicity of these patchy-quatsomes was assessed in HCT 116 cell lines and found to be suitable for fluorescence image acquisition. Fluorescence microscopy images showed that C-QS-3 and M-QS-3 are two highly selective lysosomal probes with high Pearson's correlation coefficients relative to commercial Lysotracker Red. In conclusion, C-QS-3 and M-QS-3 were useful in timedependent lysosomal tracking, fulfilling a number of requirements necessary for an efficient lysosome-selective fluorescent probe, including high stability and specificity, possibility of long-term imaging, and $\mathrm{pH}$ insensitivity. These properties make the fluorenyl-loaded QS nanoprobes particularly intriguing candidates for further studies, such as the inclusion of activities 
for lysosomal-addressed drug delivery and photodynamic therapy.

\section{EXPERIMENTAL SECTION}

Materials. 5-Cholesten-3 $\beta$-ol (Chol, purity 95\%) was purchased from Panreac (Barcelona, Spain). Hexadecyltrimethylammonium bromide (CTAB, BioUltra for molecular biology $\geq 99.0 \%$ ) was purchased from Sigma-Aldrich. MKC was purchased from FeF Chemicals. All other chemical reagents were purchased from Fisher Scientific or Sigma-Aldrich, and used as received unless otherwise noted. Milli- $Q$ water was used for all the samples preparation (Millipore Ibérica, Madrid, Spain). Ethanol (Teknocroma Sant Cugat del Vallès, Spain) was purchased in high purity. Carbon dioxide (99.9\% purity) was purchased from Carburos Metálicos S.A. (Barcelona, Spain). All reagents and solvents were purchased from commercial suppliers and used without further purification. Intermediates $\mathbf{1}$ and $\mathbf{2}$ were prepared according to their respective literature reports. ${ }^{28,29}{ }^{1} \mathrm{H}$ and ${ }^{13} \mathrm{C}$ NMR spectra were carried out in a $\mathrm{CDCl}_{3}$ solution on a Bruker AVANCE spectrometer $(400 \mathrm{MHz})$.

Synthesis of 2-(7-Bromo-9,9-diethyl-9H-fluoren-2-yl)benzo[d]thiazole (3). To a solution of $2(0.85 \mathrm{~g}, 2.0 \mathrm{mmol})$ and 2-(tri- $n$-butylstannyl)benzothiazole $(0.84 \mathrm{~g}, 2.0 \mathrm{mmol})$ in $10 \mathrm{~mL}$ of anhydrous toluene was added $\mathrm{Pd}\left(\mathrm{PPh}_{3}\right)_{4}(0.23 \mathrm{~g}, 0.2$ mmol) under $\mathrm{N}_{2}$ atmosphere. The reaction mixture was heated to reflux for $8 \mathrm{~h}$ under $\mathrm{N}_{2}$. After cooling to room temperature, the solvent was removed under reduced pressure. The crude mixture was purified by flash column chromatography using ethyl acetate/hexanes (1/10), affording the desired compound, 3 , as a white powder $(0.37 \mathrm{~g}, 43 \%) .{ }^{1} \mathrm{H}$ NMR (400 MHz, $\left.\mathrm{CDCl}_{3}\right): \delta(\mathrm{ppm}) 8.13-8.09(\mathrm{~m}, 2 \mathrm{H}), 8.04(\mathrm{~d}, J=7.9 \mathrm{~Hz}, 1 \mathrm{H})$, $7.92(\mathrm{~d}, J=7.9 \mathrm{~Hz}, 1 \mathrm{H}), 7.77(\mathrm{~d}, J=7.9 \mathrm{~Hz}, 1 \mathrm{H}), 7.62(\mathrm{~d}, J=$ $8.4 \mathrm{~Hz}, 1 \mathrm{H}), 7.50(\mathrm{~s}, 3 \mathrm{H}), 7.40(\mathrm{t}, J=7.5 \mathrm{~Hz}, 1 \mathrm{H}), 2.20-2.03$ $(\mathrm{m}, 4 \mathrm{H}), 0.35(\mathrm{t}, J=7.3 \mathrm{~Hz}, 6 \mathrm{H}) .{ }^{13} \mathrm{C}$ NMR $(101 \mathrm{MHz}$, $\left.\mathrm{CDCl}_{3}\right): \delta(\mathrm{ppm}) 168.54,154.53,153.13,150.73,143.61$, $139.80,135.29,133.12,130.53,129.17,127.80,127.51,126.67$, 126.51, 125.31, 123.35, 122.32, 121.96, 121.72, 120.33, 57.03, 32.80, 8.65. HRMS (ESI, $m / z)$ : calcd for $\mathrm{C}_{24} \mathrm{H}_{20} \mathrm{BrNS}([\mathrm{M}+$ $\mathrm{H}]^{+}$) 434.0573; found 434.0587.

Synthesis of 7-(Benzo[d]thiazol-2-yl)-9,9-diethyl-N,Ndi-n-octadecyl-9H-fluoren-2-amine (DiC18). A mixture of $3(0.13 \mathrm{~g}, 0.3 \mathrm{mmol}), \mathrm{N}, \mathrm{N}$-di- $n$-octadecylamine $(0.31 \mathrm{~g}, 0.6$ $\mathrm{mmol}), \mathrm{Pd}(\mathrm{OAc})_{2}(0.020 \mathrm{~g}, 0.03 \mathrm{mmol}),(t-\mathrm{Bu})_{3} \mathrm{P}(0.012 \mathrm{~g}$, $0.06 \mathrm{mmol})$, and $t$-BuONa $(0.058 \mathrm{~g}, 0.6 \mathrm{mmol})$ in $5 \mathrm{~mL}$ of anhydrous toluene was heated to reflux under $\mathrm{N}_{2}$ atmosphere for $16 \mathrm{~h}$. Toluene was removed in vacuo after the reaction mixture was cooled to room temperature. The residue was dissolved with $10 \mathrm{~mL}$ of $\mathrm{CH}_{2} \mathrm{Cl}_{2}$ and washed twice with $10 \mathrm{~mL}$ of brine. The organic layer was dried over $\mathrm{MgSO}_{4}$ and then concentrated under reduced pressure. The crude product was purified by flash column chromatography using ethyl acetate/ pentane $(1 / 200)$ as the eluent, providing $\mathrm{DiC} 18$ as a yellow oil (0.22 g, 84\%). ${ }^{1} \mathrm{H}$ NMR (400 $\left.\mathrm{MHz}, \mathrm{CDCl}_{3}\right): \delta$ (ppm) 8.13$8.06(\mathrm{~m}, 2 \mathrm{H}), 7.99-7.90(\mathrm{~m}, 2 \mathrm{H}), 7.62-7.58(\mathrm{~m}, 1 \mathrm{H}), 7.53-$ $7.49(\mathrm{~m}, 2 \mathrm{H}), 7.37-7.42(\mathrm{~m}, 1 \mathrm{H}), 6.66(\mathrm{~d}, J=8.4 \mathrm{~Hz}, 1 \mathrm{H})$, $6.60(\mathrm{~s}, 1 \mathrm{H}), 3.45-3.27(\mathrm{~m}, 4 \mathrm{H}), 2.20-1.99(\mathrm{~m}, 4 \mathrm{H}), 1.65(\mathrm{~s}$, $4 \mathrm{H}), 1.29(\mathrm{~s}, 60 \mathrm{H}), 0.93-0.89(\mathrm{~m}, 6 \mathrm{H}), 0.42(\mathrm{t}, J=7.2 \mathrm{~Hz}$, $6 \mathrm{H}) .{ }^{13} \mathrm{C}$ NMR (101 MHz, $\left.\mathrm{CDCl}_{3}\right): \delta(\mathrm{ppm}) 169.47,154.69$, $152.78,150.01,149.29,146.03,135.18,131.08,130.20,129.18$, $127.81,127.44,126.46,126.26,125.34,124.82,123.53,123.02$, $121.59,121.32,118.24,111.43,106.59,56.30,51.66,44.07$, $33.15,32.10,29.87,29.72,29.51,29.37,27.56,27.43,22.83$,
22.34, 14.19, 8.77. HRMS (DART, $m / z$ ): calcd for $\mathrm{C}_{60} \mathrm{H}_{94} \mathrm{~N}_{2} \mathrm{~S}$ $\left([\mathrm{M}+\mathrm{H}]^{+}\right)$875.7210; found 875.7239.

Preparation of DiC18-Loaded Quatsomes by DELOSSUSP. DELOS-SUSP, a compressed fluid-based method, was used for the preparation of DiC18-loaded QSs. Cholesterol $(111 \mathrm{mg})$ was first dissolved in $4.2 \mathrm{~mL}$ of $\mathrm{EtOH}$ at a working temperature, $T_{\mathrm{w}}\left(T_{\mathrm{w}}=308 \mathrm{~K}\right)$, along with a determined amount of DiC18 (described below and in the Supporting Information). The solution was then added to a high-pressure vessel $(V=11.8 \mathrm{~mL})$ at atmospheric pressure and $T_{\mathrm{w}}$. After 20 min of equilibration, the vessel was pressurized with $\mathrm{CO}_{2}$ at the working pressure, $P_{\mathrm{w}}\left(P_{\mathrm{w}}=10 \mathrm{MPa}\right)$, to have an expanded liquid ethanol solution with a molar fraction of $\mathrm{CO}_{2}$ of $\mathrm{X}_{\mathrm{CO}_{2}}=$ 0.63. The reactor was kept at the working condition for $1 \mathrm{~h}$ to homogenize the system. The organic solution was then depressurized over $35 \mathrm{~mL}$ of water, where $100 \mathrm{mg}$ of CTAB (or $202 \mathrm{mg}$ of MKC) had been previously dissolved. $\mathrm{N}_{2}$ at 10 $\mathrm{MPa}$ was added to the vessel during the depressurization in order to maintain constant $P_{\mathrm{w}}$ inside. The vessel was equipped with a gas filter, to prevent any unsolved compound present in the $\mathrm{CO}_{2}$-expanded solution to reach the aqueous solution of the surfactant. With this one-step method, unilamellar vesicles with high vesicle-to-vesicle homogeneity were prepared, enabling the straightforward loading of quatsomes with hydrophobic compounds such as DiC18.

The loading, $L$, is expressed as the ratio $L=$ moles $_{\mathrm{DiC18}} /$ $\left(\right.$ moles $_{\text {cholesterol }}+$ moles $\left._{\text {surfactant }}\right)$. In the case of QSs made of $\mathrm{CTAB} /$ cholesterol (1:1 molar ratio), three different samples, referred to as C-QS-1, -2, and -3, having $L=0.9,7$, and $13 \times$ $10^{-3}$, respectively, were prepared. In the case of $\mathrm{MKC} /$ cholesterol (1:2 molar ratio) QSs, three samples, M-QS-1, -2, and -3 ,with $L=0.5,4.8$, and $9.7 \times 10^{-3}$, respectively, were synthesized. The concentrations of $\mathrm{DiC18}$ in the respective samples were determined as explained in the Supporting Information, whereas the nominal concentrations of surfactants and cholesterol were used for the determination of $L$. All samples were purified by diafiltration by using the Kros Flo Research Ii $i$ TFF System (Spectrum Labs) equipped with an mPES Micro Kros filter column (100 kDa molecular weight cutoff) to remove ethanol and excess of CTAB or MKC.

Preparation of DiC18 NPs by Reprecipitation. A solution of $0.5 \mathrm{mM} \mathrm{DiC18}$ in THF was filtered using a 220 $\mathrm{nm}$ pore size Teflon filter, and $100 \mu \mathrm{L}$ of the filtered solution was then dropped into $9.9 \mathrm{~mL}$ of Milli-Q water at room temperature under vigorous stirring for $1 \mathrm{~h}$.

Physical Characterization of DiC18-Loaded Quatsomes. Size and zeta potential of DiC18-loaded quatsomes were studied using dynamic light scattering (Malvern Zetasizer Nano ZS, Malvern Instruments, U.K.) with noninvasive backscattering optics, equipped with a $\mathrm{He}-\mathrm{Ne}$ laser at 633 $\mathrm{nm}$. All values reported were the average of three consecutive measurements of the same samples at $25{ }^{\circ} \mathrm{C}$ (standard deviation over the three measurements $<7 \%$ ). Values were reported as average hydrodynamic diameters \pm PDI (polydispersity index in $\mathrm{nm}$ ). CryoTEM images were acquired with a JEOL JEM microscope (JEOL, Tokyo, Japan) operating at 120 $\mathrm{kV}$. The sample was placed in a copper grid coated with a perforated polymer film and then plunged into liquid ethane to freeze it. It was then placed into the TEM.

Photophysical Properties Measurements. Linear absorption, fluorescence, and excitation spectra of DiC18, C-QS1, -2, and -3, and M-QS-1, -2, and -3 were investigated in 
spectroscopic grade HEX, CHX, TOL, DCM, ACN, DMSO, glycerol, and Milli-Q water at room temperature. The steadystate absorption spectra were measured with a Tecan Infinite M200 PRO plate reader spectrometer in $1 \mathrm{~cm}$ path length quartz cuvettes. The fluorescence and excitation spectra were obtained using an Edinburgh Instruments FLS980 fluorescence spectrometer. Solutions studied during all of the measurements had optical densities less than 0.1. The fluorescence spectra were corrected for the spectral responsivity of the photomultiplier tube detector. Excitation anisotropy measurements for DiC18 were performed in a viscous solvent to impede molecular rotational relaxation. The fluorescence quantum yields were determined relative to 9,10-diphenylanthracene in cyclohexane $(\Phi=0.95)$ as the standard. ${ }^{30,32}$ The values were calculated according to eq 1

$$
\phi_{\text {sample }}=\phi_{\text {ref }} \frac{\mathrm{OD}_{\text {ref }} I_{\text {sample }} n_{\text {sample }}^{2}}{\mathrm{OD}_{\text {sample }} I_{\text {ref }} n_{\text {ref }}^{2}}
$$

where $\Phi$ is the quantum, $I$ is the integrated emission signal, OD is the optical density at the excitation wavelength, and $n$ is the refractive index; subscript "ref" stands for reference sample, "sample" stands for experimental sample.

It is important to take into account that at the concentrations studied, Quatsomes scatter UV-vis light. To accurately measure and calculate the quantum yield for C-QS-1 and MQS-1 (samples with a low absorption/scattering ratio), contribution of scattered light was subtracted from the absorption spectra. The signal detected from the spectrophotometer can be partitioned into light that is actually absorbed $\left(A_{\text {corrected }, \lambda}\right)$ and the apparent absorption that is due to light scattering at a given wavelength $\left(A_{\mathrm{LS}, \lambda}\right)$. The apparent absorption spectrum of plain QSs can be modeled with eq 2, in accordance with Rayleigh-Tyndall approximation

$$
A_{\mathrm{LS}, \lambda}=a \lambda^{n}
$$

where $a$ and $n$ were determined by the least squares fitting of the measured absorption spectrum at wavelengths larger than those in which absorption of DiC18 was observed. After scattering subtraction, the condition $\mathrm{Abs}_{333 \mathrm{~nm}}=0.32 \mathrm{Abs}_{\mathrm{MAX}}$ verified for C-QS-2 and -3 samples and, therefore, independent of the DiC18 loading, was also verified for C-QS-1. However, owing to this mathematical treatment for scattering removal, the fluorescence quantum yield of C-QS-1 shall be considered as an approximated value and simply used for comparison purpose with the other samples studied.

pH Stability Measurements. The steady-state absorption spectra of C-QS-3 and M-QS-3 at various $\mathrm{pHs}$ in the PBS solution were recorded using a Tecan Infinite M200 PRO plate reader spectrometer in $1 \mathrm{~cm}$ path length quartz cuvettes. Likewise, $\mathrm{pH}$-dependent fluorescence spectra were obtained using an Edinburgh Instruments FLS980 fluorescence spectrometer.

Cell Viability. To assess the cytotoxicity of DiC18, C-QS-1, -2, and -3, and M-QS-1, -2, and -3, HCT 116 and HeLa cells were cultured in the minimum Eagle's essential medium (MEM) and Dulbecco's modified Eagle's medium (DMEM) cell medium supplemented with $10 \%$ fetal bovine serum, $1 \%$ penicillin, and streptomycin at $37{ }^{\circ} \mathrm{C}$ and $5 \% \mathrm{CO}_{2}$. Cells were placed in 96 well plates and incubated until there were no fewer than $6 \times 10^{3}$ cells per well for the experiments. Next, HCT 116 cells were incubated with different concentrations of DiC18 $(1.25,2.5,5,10,20$, and $40 \mu \mathrm{M})$ for an additional $22 \mathrm{~h}$. HeLa cells were incubated with different concentrations of C-QS-1, -2 , and $-3(0.022,0.044,0.088,0.175,0.35$, and $0.70 \mathrm{mM})$ and M-QS-1, -2, and -3 (0.044, 0.088, 0.18, and $0.35 \mathrm{mM})$ for an additional $22 \mathrm{~h}$, where the values within parentheses refer to the nominal concentrations of the surfactants. After that, $20 \mu \mathrm{L}$ of the CellTiter 96 Aqueous One solution reagent (for MTS assay) was added into each well, followed by further incubation for $2 \mathrm{~h}$ at $37^{\circ} \mathrm{C} . .^{17,31,36}$ The respective absorbance values were read on a Tecan Infinite M200 PRO plate reader spectrometer at $490 \mathrm{~nm}$ to determine the relative amount of formazan produced. Cell viabilities were calculated on the basis of the following equation (eq 3 )

$$
\text { cell viability }(\%)=\frac{\mathrm{Abs}_{490 \mathrm{~nm}}-\mathrm{Abs}_{490 \mathrm{~nm}}^{\mathrm{D}}}{\mathrm{Abs}_{490 \mathrm{~nm}}^{\mathrm{c}}-\mathrm{Abs}^{\mathrm{D} 2}{ }_{490 \mathrm{~nm}}} \times 100 \%
$$

where $\mathrm{Abs}_{490 \mathrm{~nm}}^{\mathrm{s}}$ is the absorbance of the cells incubated with different concentrations of experimental probe solutions, $\mathrm{Abs}^{\mathrm{D}}{ }_{490 \mathrm{~nm}}$ is the absorbance of cell-free well containing only dye at the concentration that was studied, $\mathrm{Abs}^{\mathrm{c}}{ }_{490 \mathrm{~nm}}$ is the absorbance of cells only incubated in the medium, $\mathrm{Abs}^{\mathrm{D} 2}{ }_{490 \mathrm{~nm}}$ is the absorbance of the cell-free well.

Cell Imaging. HCT 116 cells were placed onto poly-Dlysine-coated coverslips and transferred into 24-well glass plates $\left(5 \times 10^{4}\right.$ cells per well), and incubated for $48 \mathrm{~h}$ before incubating with the quatsome. A stock solution of the fluorescent probe of DiC18 dissolved in DMSO was prepared as a $2 \mathrm{mM}$ solution. The solution was diluted to $5,10,15$, and $20 \mu \mathrm{M}$ by the complete growth medium, DMEM, and freshly incubated with HCT 116 cells for $2 \mathrm{~h}$. After incubation, the dye solutions were extracted and the coverslipped cells were washed twice with the PBS solution. Cells were then fixed with $3.7 \%$ formaldehyde solution in the PBS solution for $10 \mathrm{~min}$. The fixing agent was extracted and washed twice with PBS. To reduce the autofluorescence, a fresh solution of $\mathrm{NaBH}_{4}(1 \mathrm{mg} /$ $\mathrm{mL}$ ) in the PBS buffer was used to twice treat the fixed cells for $10 \mathrm{~min}$. The coverslipped cells were then washed twice with PBS and then with deionized (DI) water and mounted on microscope slides using an antifade mounting media (Prolong Gold).

Stock solutions of C-QS-1, -2, and -3 were diluted to a nominal concentration of $0.022 \mu \mathrm{M}$ of CTAB by the DMEM cell medium, whereas stock solutions of M-QS-1, -2, and -3 were diluted to a nominal concentration of $0.044 \mu \mathrm{M}$ of MKC by the DMEM cell medium. The incubation and fixation procedures were repeated for these six experimental solutions. Fluorescence microscopy images were observed and recorded on an inverted microscope (Olympus IX70) equipped with a QImaging cooled charge-coupled device (CCD) and a $100 \mathrm{~W}$ mercury lamp. To improve the fluorescence background-toimage ratios, fluorescence images were obtained using a customized filter cube (Ex: 377/50; DM: 409; Em: 460/60).

Colocalization Study. To investigate the efficiency and specificity of C-QS-3 and M-QS-3, HCT 116 and COS-7 cell lines were employed. All cells were seeded on poly-D-lysinecoated coverslips at the density of $4 \times 10^{4}$ cells per well and incubated for $48 \mathrm{~h}$. Stock solutions of C-QS-3 and M-QS-3 dissolved in DI water were prepared at a nominal concentration of $1 \mathrm{mM}$. Lysotracker Red DND-99 (LT Red) was purchased as a $1 \mathrm{mM}$ stock solution in anhydrous DMSO, and MitoTracker Red FM (MT Red) containing $50 \mu \mathrm{g}$ of lyophilized solid per vial was dissolved in $69 \mu \mathrm{L}$ of DMSO 
and prepared as a $1 \mathrm{mM}$ stock solution. For coincubating cells with C-QS-3 or M-QS-3 and LT Red, the stock solution was diluted to $0.022 \mathrm{mM}$ for CTAB and $0.044 \mathrm{mM}$ for MKC and $75 \mathrm{nM}$ LT Red with the DMEM cell medium and freshly placed over cells for a $2 \mathrm{~h}$ incubation period. For coincubating cells with C-QS-3 or M-QS-3 and MT Red, the stock solution was diluted to $0.022 \mathrm{mM}$ for CTAB and $0.044 \mathrm{mM}$ for MKC with the DMEM cell medium and freshly incubated with cells for $2 \mathrm{~h}$, followed by incubation with $400 \mathrm{nM}$ MT Red in the DMEM cell medium for an additional $45 \mathrm{~min}$. Cells were washed twice with PBS and then fixed with $3.7 \%$ formaldehyde solution in PBS for $10 \mathrm{~min}$. The fixing agent was extracted and washed twice with PBS. A fresh solution of $\mathrm{NaBH}_{4}(1 \mathrm{mg} / \mathrm{mL})$ in PBS was used to twice treat the fixed cells for $10 \mathrm{~min}$. The coverslipped cells were then washed twice with PBS and then with deionized water and mounted on microscope slides using an antifade mounting media (Prolong Gold). Fluorescence images of the fixed cells were obtained using a customized filter cube (Ex: 377/50; DM: 409; Em: 460/60) for C-QS-3 and MQS-3; a Texas Red filter cube (Ex: 562/40; DM: 593; Em: 624/40) was employed for Lysotracker Red and MitoTracker Red FM imaging. Pearson's correlation coefficient for C-QS-3 and M-QS-3 was calculated using Fiji, a freely available image processing software.

Time-Dependent Lysosome Tracking Experiment. To track the QS probe cellular distribution in cancer cells, HCT 116 cells were placed onto poly-D-lysine-coated coverslips and transferred into 24 -well glass plates $\left(5 \times 10^{4}\right.$ cells per well $)$ and then incubated for $48 \mathrm{~h}$ before incubating with the QS probe. The stock solution was diluted to a final concentration $(0.022$ $\mathrm{mM}$ for CTAB and $0.044 \mathrm{mM}$ for MKC) and $75 \mathrm{nM}$ LT Red with the DMEM cell medium. Cells were incubated with solutions for a $2 \mathrm{~h}$ incubation period and washed thoroughly and then incubated with fresh DMEM medium for an additional 2, 4, and $6 \mathrm{~h}$. After incubation, cells were washed twice with PBS and then fixed with 3.7\% formaldehyde solution in PBS for $10 \mathrm{~min}$. The fixing agent was extracted and washed twice with PBS. A fresh solution of $\mathrm{NaBH}_{4}(1 \mathrm{mg} / \mathrm{mL})$ in PBS was used to twice treat the fixed cells for $10 \mathrm{~min}$. The coverslipped cells were then washed with the PBS buffer twice and then with deionized water and mounted on microscope slides with Prolong gold mounting media. Fluorescence microscopy images were recorded on an inverted microscope (Olympus IX70) equipped with a QImaging cooled CCD and a $100 \mathrm{~W}$ mercury lamp. Fluorescence images of the fixed cells were taken using a customized filter cube (Ex: 377/50; DM: 409; Em: 460/40) for C-QS-3 and M-QS-3; a Texas Red filter cube (Ex: 562/40; DM: 593; Em: 624/40) was utilized for imaging Lysotracker Red.

\section{ASSOCIATED CONTENT}

\section{(S Supporting Information}

The Supporting Information is available free of charge on the ACS Publications website at DOI: 10.1021/acsomega.7b00779.

General methods for physicochemical, spectroscopic, and optical characterizations for compounds, nanovesicles, and nanoparticles, including Figures S1-S16 and Tables S1 and S2 (PDF)

\section{AUTHOR INFORMATION}

\section{Corresponding Authors}

*E-mail: ventosa@icmab.es (N.V.).
*E-mail: vecianaj@icmab.es (J.V.).

*E-mail: belfield@njit.edu (K.D.B.).

ORCID $\odot$

Nora Ventosa: 0000-0002-8008-4974

Jaume Veciana: 0000-0003-1023-9923

Kevin D. Belfield: 0000-0002-7339-2813

\section{Author Contributions}

${ }^{\S}$ X.L. and A.A. contributed equally to this work.

Notes

The authors declare no competing financial interest.

\section{ACKNOWLEDGMENTS}

This work was supported by the DGI, Spain, "Grants BEWELL CTQ2013-40480-R" and "Mother MAT 2016-80826R”, by AGAUR, Generalitat de Catalunya, "Grant 2014-SGR17", the Networking Research Center on Bioengineering, Biomaterials, and Nanomedicine (CIBER-BBN), and the Spanish Ministry of Economy and Competitiveness, through the "Severo Ochoa" Programme for Centres of Excellence in R\&D (SEV-2015-0496) through FIP Flowers project. Characterizations of nanovesicles were made at the ICTS "NANBIOSIS", more specifically by the U6 unit of CIBER$\mathrm{BBN}$. The research leading to these results received funding from the People Programme (Marie Curie Actions) of the European Union's Seventh Framework Programme FP7/ 2007-2013 under REA grant agreement no. 607721 (Nano2Fun) A.A. is enrolled in the Materials Science Ph.D. program of UAB. K.D.B. and X.L. acknowledge support from the National Science Foundation (CBET-1517273).

\section{REFERENCES}

(1) Yue, X.; Morales, A. R.; Githaiga, G. W.; Woodward, A. W.; Tang, S.; Sawada, J.; Komatsu, M.; Liu, X.; Belfield, K. D. RGD-conjugated two-photon absorbing near-IR emitting fluorescent probes for tumor vasculature imaging. Org. Biomol. Chem. 2015, 13, 10716-10725.

(2) Yanez, C. O.; Morales, A. R.; Yue, X.; Urakami, T.; Komatsu, M.; Järvinen, T. A. H.; Belfield, K. D. Deep vascular imaging in wounds by two-photon fluorescence microscopy. PLoS One 2013, 8, No. e67559.

(3) Wang, X.; Morales, A. R.; Urakami, T.; Zhang, L.; Bondar, M. V.; Komatsu, M.; Belfield, K. D. Folate receptor-targeted aggregationenhanced near-IR emitting silica nanoprobe for one-photon in vivo and two-photon ex vivo fluorescence bioimaging. Bioconjugate Chem. 2011, 22, 1438-1450.

(4) Ha-Thi, M.-H.; Penhoat, M.; Drouin, D.; Blanchard-Desce, M.; Michelet, V.; Leray, I. Synthesis, fluorescence, and two-photon absorption of bidentate phosphane oxide derivatives: Complexation with $\mathrm{Pb}^{2+}$ and $\mathrm{Cd}^{2+}$ cations. Chem. - Eur. J. 2008, 14, 5941-5950.

(5) Maeda, H.; Tierney, D. L.; Mariano, P. S.; Banerjee, M.; Cho, D.; Yoon, U. Lariat-crown ether based fluorescence sensors for heavy metal ions. Tetrahedron 2008, 64, 5268.

(6) Zhang, M.; Yu, M.; Li, F.; Zhu, M.; Li, M.; Gao, Y.; Li, L.; Liu, Z.; Zhang, J.; Zhang, D.; Yi, T.; Huang, C. A highly selective fluorescence turn-on sensor for cysteine/homocysteine and its application in bioimaging. J. Am. Chem. Soc. 2007, 129, 10322-10323.

(7) Yue, X.; Yanez, C. O.; Yao, S.; Belfield, K. D. Selective cell death by photochemically induced $\mathrm{pH}$ imbalance in cancer cells. J. Am. Chem. Soc. 2013, 135, 2112-2115.

(8) Fadhel, A. A.; Yue, X.; Zadeh, E. H. G.; Bondar, M. V.; Belfield, K. D. Pegylated and nanoparticle-conjugated sulfonium salt photo triggers necrotic cell death. Int. J. Nanomed. 2016, 11, 6161-6168.

(9) Yao, S.; Schafer-Hales, K. J.; Belfield, K. D. A new water-soluble near-neutral ratiometric fluorescent $\mathrm{pH}$ indicator. Org. Lett. 2007, 9, $5645-5648$.

(10) Belfield, K. D.; Bondar, M. V.; Morales, A. R.; Yue, X.; Luchita, G.; Przhonska, O. V.; Kachkovsky, O. D. Two-photon absorption and 
time-resolved stimulated emission depletion spectroscopy of a new fluorenyl derivative. ChemPhysChem 2012, 13, 3481-3491.

(11) Khaokeaw, C.; Sukwattanasinitt, M.; Rashatasakhon, P. Salicylyl fluorene derivatives as fluorescent sensors for $\mathrm{Cu}(\mathrm{II})$ ions. J. Fluoresc. 2016, 26, 745-752.

(12) Yao, S.; Ahn, H. Y.; Wang, X.; Fu, J.; Stryland, E. W. V.; Hagan, D. J.; Belfield, K. D. Donor-acceptor-donor fluorene derivatives for two-photon fluorescence lysosomal imaging. J. Org. Chem. 2010, 75, 3965-3974.

(13) Yamada, A.; Hiruta, Y.; Wang, J.; Ayano, E.; Kanazawa, H. Design of environmentally responsive fluorescent polymer probes for cellular imaging. Biomacromolecules 2015, 16, 2356-2362.

(14) Cheng, L.; He, W.; Gong, H.; Wang, C.; Chen, Q.; Cheng, Z.; Liu, Z. PEGylated micelle nanoparticles encapsulating a nonfluorescent near-infrared organic dye as a safe and highly-effective photothermal agent for in vivo cancer therapy. Adv. Funct. Mater. 2013, 23, 5893-5902.

(15) Ferrer-Tasies, L.; Calvo, E. M.; Sarabia, M. C.; Arzo, M. A.; Angelova, A.; Lesieur, S.; Ricart, S.; Faraudo, J.; Ventosa, N.; Veciana, J. Quatsomes: Vesicles formed by self-assembly of sterols and quaternary ammonium surfactants. Langmuir 2013, 29, 6519-6528.

(16) Cabrera, I.; Elizonda, E.; Esteban, O.; Corchero, J. L.; Melgarejo, M.; Pulido, D.; Cordoba, A.; Moreno, E.; Unzueta, U.; Vazquez, E.; Abasolo, I.; Schwartz, S., Jr.; Villaverde, A.; Albericio, F.; Royo, M.; Parajo, M. F. G.; Ventosa, N.; Veciana, J. Multifunctional nanovesiclebioactive conjugates prepared by a one-step scalable method using $\mathrm{CO}_{2}$-expanded solvents. Nano Lett. 2013, 13, 3766-3774.

(17) Wang, X.; Nguyen, D. M.; Yanez, C. O.; Rodriguez, L.; Ahn, H. Y.; Bondar, M. V.; Belfield, K. D. High fidelity hydrophilic probe for two-photon fluorescence lysosomal imaging. J. Am. Chem. Soc. 2010, 132, 12237-12239.

(18) Yapici, N. B.; Bi, Y.; Li, P.; Chen, X.; Yan, X.; Mandalapu, S.; Faucett, M.; Jockusch, S.; Ju, J.; Gibson, K. M.; Pavan, W. J.; Bi, L. Highly stable and sensitive fluorescent probes (lysoprobes) for lysosomal labeling and tracking. Sci. Rep. 2015, 5, No. 8576.

(19) Maes, H.; Agostinis, P. Autophagy and mitophagy interplay in melanoma progression. Mitochondrion 2014, 19, 58-68.

(20) Thorburn, A.; Thamm, D. H.; Gustafson, D. L. Autophagy and cancer therapy. Mol. Pharmacol. 2014, 85, 830-838.

(21) He, X.; Li, J.; An, S.; Jiang, C. pH-sensitive drug-delivery systems for tumor targeting. Ther. Delivery 2013, 4, 1499-1510.

(22) Kim, S. E.; Overholtzer, M. Autophagy proteins regulate cell engulfment mechanisms that participate in cancer. Semin. Cancer Biol. 2013, 23, 329-336.

(23) Hamasaki, M.; Furuta, N.; Matsuda, A.; Nezu, A.; Yamamoto, A.; Fujita, N.; Oomori, H.; Noda, T.; Haraguchi, T.; Hiraoka, Y.; Amano, A.; Yoshimori, T. Autophagosomes form at ER-mitochondria contact sites. Nature 2013, 495, 389-393.

(24) Hughes, A. L.; Gottschling, D. E. An early age increase in vacuolar $\mathrm{pH}$ limits mitochondrial function and lifespan in yeast. Nature 2012, 492, 261-265.

(25) Chen, X.; Bi, Y.; Wang, T.; Li, P.; Yan, X.; Hou, S.; Bammert, C. E.; Ju, J.; Gibson, K. M.; Pavan, W. J.; Bi, L. Lysosomal targeting with stable and sensitive fluorescent probes (superior lysoprobes): Applications for lysosome labeling and tracking during apoptosis. Sci. Rep. 2015, 5, No. 9004.

(26) Andrade, C. D.; Yanez, C. O.; Qaddoura, M. A.; Wang, X.; Arnett, C. L.; Coombs, S. A.; Yu, J.; Bassiouni, R.; Bondar, M. V.; Belfield, K. D. Two-photon fluorescence lysosomal bioimaging with a micelle-encapsulated fluorescent probe. J. Fluoresc. 2011, 21, 12231230.

(27) Elizondo, E.; Larsen, J.; Hatzakis, N. S.; Cabrera, I.; Bjornholm, T.; Veciana, J.; Stamou, D.; Ventosa, N. Influence of the preparation route on the supramolecular organization of lipids in a vesicular system. J. Am. Chem. Soc. 2012, 134, 1918-1921.

(28) Peterson, J. J.; Werre, M.; Simon, Y. C.; Coughlin, E. B.; Carter, $\mathrm{K}$. R. Carborane-containing polyfluorene: $o$-carborane in the main chain. Macromolecules 2009, 42, 8594-8598.
(29) Liu, X. G.; Sun, W. Synthesis, photophysics, and reverse saturable absorption of bipyridyl platinum(II) bis(acetylide) complexes bearing aromatic electron-withdrawing substituents on the acetylide ligands. J. Phys. Chem. A 2014, 118, 10318-10325.

(30) Kurhuzenkau, S. A.; Woodward, A. W.; Yao, S.; Belfield, K. D.; Shaydyuk, Y. O.; Sissa, C.; Bondar, M. V.; Painelli, A. Ultrafast spectroscopy, superluminescence and theoretical modeling of a twophoton absorbing fluorene derivative. Phys. Chem. Chem. Phys. 2016, 18, 12839-12846.

(31) Zhang, Y.; Yue, X.; Kim, B.; Yao, S.; Bondar, M. V.; Belfield, K. D. Serum albumin (BSA) nanoparticles with fluorogenic near-IRemitting squarine dyes. ACS Appl. Mater. Interfaces 2013, 5, 87108717.

(32) Belfield, K. D.; Morales, A. R.; Kang, B. S.; Hales, J. M.; Hagan, D. J.; Stryland, E. W. V.; Chapela, V. M.; Percino, J. Synthesis, characterization and optical properties of new two-photon absorbing fluorene derivatives. Chem. Mater. 2004, 16, 4634-4641.

(33) Cooper, G. M.; Robert, E. H. The Cell: A Molecular Approach, 6th ed.; Sinauer Associates: Sunderland, MA, 2013, pp 412-416.

(34) Kalbácová, M.; Verdánová, M.; Mravec, F.; Halasová, T.; Pekai, $M$. Effect of $C T A B$ and $C T A B$ in the presence of hyaluronan on selected human cell types. Colloids Surf., A 2014, 460, 204-208.

(35) Vlachy, N.; Touraud, D.; Heilmann, J.; Kunz, W. Determining the cytotoxicity of catanionic surfactant mixtures on $\mathrm{HeLa}$ cells. Colloids Surf., B 2009, 70, 278-280.

(36) Sui, B.; Liu, X.; Wang, M.; Belfield, K. D. Highly selective fluorescence turn-on sensor for extracellular $\mathrm{Ca}^{2+}$ detection. Chem. Eur. J. 2016, 22, 10351-10354. 